\title{
Correspondence
}

\section{Blind tracheal intubation through the laryngeal mask}

\section{To the Editor:}

Drs. Godley and Ramachandra Reddy report a case of awake blind tracheal intubation through the laryngeal mask.' After insertion of the laryngeal mask, they confirmed the correct position of the mask using a fibreoptic bronchoscope. They removed the fibrescope and then blindly passed a tracheal tube through the laryngeal mask into the trachea. They claim that blind insertion of a tracheal tube may fail if the position of the mask has not been confirmed.'

The success rate of blind tracheal intubation through the laryngeal mask at the first attempt is up to about $70 \%, 2,3$ it may be very low even after repetitive attempts, by the choice of a tracheal tube. ${ }^{3}$ In these studies, the position of the laryngeal mask was not assessed. I therefore examined the success rate of this blind technique after correct positioning of the laryngeal mask.

In 10 anaesthetized and paralyzed patients, the laryngeal mask was inserted and the position of the mask was assessed using a fibrescope. The glottis was always seen just below the grille of the mask, and the oesophagus was not seen. The fibrescope was removed and a Portex $6.0-\mathrm{mm}$ cuffed tube waspassed blindly through the mask, without manipulation of the patient's head and neck. In 6 of 10 patients, the tube was inserted into the oesophagus at the first attempt. This indicates that even when the position of the laryngeal mask is optimal, tracheal intubation through the mask often fail when the tube is inserted blindly.

A higher success rate may be obtained when the patients' head and neck are manipulated during the blind intubation, but it may not be possible in patients with difficult airways. In contrast, when a tracheal tube is passed over a fibrescope through the laryngeal mask, intubation is almost always successful at the first attempt without manipulation of the head and neck both in anaesthetized ${ }^{4}$ and in awake patients. ${ }^{5}$ I suggest that the use of a fibrescope for tracheal intubation through the laryngeal mask is more reliable than the blind technique.

Takashi Asai MD

Department of Anaesthetics and Intensive Care Medicine University of Wales College of Medicine

Heath Park, Cardiff, CF4 4XN

United Kingdom.

\section{REFERENCES}

1 Godley M, Ramachandra Reddy AR. Use of LMA for awake intubation for Caesarean section. Can J Anaesth 1996; 43: 299-302.

2 Heath ML, Allagain J. Intubation through the laryngeal mask. A technique for unexpected difficult intubation. Anaesthesia 1991; 46: 545-8.

$3 \mathrm{Lim} S L$, Tay DHB, Thomas E. A comparison of three types of tracheal tube for use in laryngeal mask assisted blind orotracheal intubation. Anaesthesia 1994; 49: 255-7.
4 Asai T, Barclay K, Power l, Vaughan RS. Cricoid pressure impedes placement of the laryngeal mask airway and subsequent tracheal intubation through the mask. $\mathrm{Br} J$ Anaesth 1994; 72: 47-51.

5 Asai $T$. Use of the laryngeal mask for tracheal intubation in patients at increased risk of aspiration of gastric contents. Anesthesiology 1992; 77: 1029-30.

\section{$R E P L Y$}

We would like to emphasize that our patient with pre eclampsia, fetal distress and bleeding tendency, was not paralyzed. She was able to tolerate the placement of the LMA with adequate topical anaesthesia and correct placement was ensured using the fibrescope. With the patient conscious and breathing spontaneously, we were able to provide good oxygenation and unobstructed ventilation. The tracheal tube was inserted blindly, connected to the circle system and the capnograph confirmed the correct placement of the tracheal tube in the trachea. Using a fibrescope would also have confirmed successful intubation. However, this may have increased airway resistance and decreased oxygen supply.

We conclude that the use of the fibrescope in spontaneously breathing patients may obstruct the upper airway. Patients who are pregnant and experiencing fetal distress are particularly at risk. However, the success rate of blind intubation through correctly placed LMA's in spontaneously breathing, conscious patients does need further study.

Mark B. Godley MB ChB FRCPC

Ramachandra Reddy BSC MBBS DA FRCPC

Vancouver, B.C.

\section{Lung ventilation and bronchopleural fistula}

To the Editor:

A 46-yr-old man was admitted to ICU with streptococcal pneumonia. Lung ventilation parameters were: pressure control (PC) $30 \mathrm{cmH}_{2} \mathrm{O}$, rate $20 \cdot \mathrm{min}^{-1}$, PEEP $7.5 \mathrm{cmH}_{2} \mathrm{O}, \mathrm{FIO}_{2}$ 0.8 . The CXR revealed bilateral alveolar infiltrates and a small right sided pneumothorax with a \#20 Fr chest tube.

On day 3 due to an enlarging pneumothorax, the chest tube was changed to \#28 Fr resulting in a large air leak (estimated $\left.10 \mathrm{~L} \cdot \mathrm{min}^{-1}\right)$ and a decrease in the patient's expired tidal volume to $100 \mathrm{ml}$. However, PC, IMV, manual ventilation and insertion of a second chest tube failed to improve the ABGs. A left sided \#39 Fr. double lumen tube (DLT) was placed. Neither high frequency jet ventilation (HFJV) to both lungs nor PCV to the left lung with CPAP to the right lung were successful. Adequate ventilation $\left(\mathrm{PaCO}_{2} 28 \mathrm{mmHg}, \mathrm{PaO}_{2} 106\right.$ $\mathrm{mmHg}$ ) was achieved with the following ventilatory manipulations: right lung - HFJV driving pressure $8 \mathrm{psi}$, rate $120 \cdot \mathrm{min}^{-1}$, inspiratory time $30 \%$, PEEP $10 \mathrm{cmH}_{2} \mathrm{O}$; left lung - $\mathrm{PC} 20 \mathrm{cmH}_{2} \mathrm{O}$, rate $20 \cdot \mathrm{min}^{-1}$, PEEP $10 \mathrm{cmH}_{2} \mathrm{O}, \mathrm{FIO}_{2}$ 